\title{
Therapeutic spaces of care farming: transformative or ameliorating?
}

\section{$\underline{\text { Abstract }}$}

Since Wil Gesler's earliest articulation (W M Gesler, 1992; Gesler, 1996) key thinkers in the field of therapeutic landscapes have sought to emphasise the embodied, contextual and wholly relational nature of the relationship that exists between people and place. However, the extant research has tended to focus on the relational healing experience as this occurs 'in the moment' and with reference to a specific location or site of healing, with less attention being paid to what happens to people when they return to their ordinary or everyday places. In this paper, we reflect on findings from visual ethnographic work (including photography and film) that explored the therapeutic landscape experiences of people with intellectual disabilities engaged in care farming interventions for health and wellbeing. The study also recruited farm staff and family members or carers to take part, and comprised of 20 participants in total. Having identified a gap in our understanding, consideration is given to wider impact that engaging in these sorts of activities had on the everyday lives of the participants in this study. We argue that this study has identified two types of therapeutic journey that broadly fit the experiences of study participants. The first type of journey denotes landscape experiences that are transformative. Here the therapeutic power of the care farm landscape resides in the ability of activities conducted on care farms to influence other aspects of participants' lives in ways that promote wellbeing. By contrast, there is another type of journey where the therapeutic power of the care farm resides in its ability to ameliorate challenging or harmful life situations, thus offering people a temporary site of respite or refuge. We conclude that these findings denote an important development for this sub-field of health geography, not only because they draw attention to the transformative power 
of the therapeutic encounter, but also the broader socio-spatial environments in which people live and ways in which these can limit that power.

\section{1. Introducing therapeutic landscapes: a relational approach}

Within the field of health geography, the therapeutic landscape concept has emerged as a dominant framework for organising ideas about people's experience of place and how these experiences impact on health and wellbeing (DeMiglo and Williams, 2008). First introduced by Wil Gesler (1992) this approach to health geography adopts explicitly socio-cultural frameworks for understanding the complex intermingling of physical, social and symbolic processes that determine a place's potential to positively or negatively affect health (Gesler, 1992). On this view, understanding the role of place in promoting the health of populations involves attending to the way in which various environmental, societal and individual factors work together in certain natural or built environments to produce positive social and psychological outcomes (Jones \& Moon, 1993; Kearns \& Gesler, 1998b; Kearns, 1993b). Studies of therapeutic landscapes within the field of health geography have, therefore, tended to focus on qualitative explorations of the processes through which

therapeutic places are co-constructed and emphasise the dynamic, fluid and relational aspects of health within a variety of settings (Bell et al., 2018). These insights suggest that the therapeutic power of different spaces are not constant or stable, but are influenced by a variety of individual, material and wider socio-political factors and relations, such as media attitudes to particular space types (Milligan and Bingley, 2007); the weather and changing seasons (Collins and Kearns, 2007); or a person's emotional state at the time of the experience (Laws, 2009). On this rendering, landscapes do not possess inherent features with the capacity to enhance or restore wellbeing; rather therapeutic properties are relational properties that reside in people's interactions with features of their environment. In recent years, these 
observations have encouraged health geographers to focus on the various assemblages of bodies (both human and non-human) and things that can affect a space 'becoming therapeutic' (Gorman, 2017, p. 318) and ways in which these place experiences are enacted over time or moment-moment (Andrews, Chen and Myers, 2014). Importantly however, a comprehensive relational analysis of the therapeutic potential of a particular environmental setting must take into account not only the specific forms of engagement that take place within that setting but also the wider network of socio-environmental relations within which an individual is embedded (Conradson, 2005). Indeed, in order to gain an understanding of the potential significance of particular instances of self-landscape encounter it is necessary to obtain some sense of the wider context through which these types of engagement are made intelligible.

Research in the field of therapeutic landscapes has typically focussed on the relational healing experience as this occurs 'in the moment' and with reference to a specific location or site of healing, with less attention being paid to what happens to people when they return to their ordinary or everyday places. As Willis (2009) highlights, this makes it very difficult to ascertain the wider or more long term benefits of these kinds of interventions. Whist most therapeutic landscape experiences do involve the temporary movement away from an everyday domestic location, it must be conceded that the physiological or emotional effects of this relocation are, in part, attributable to an individual becoming engaged in a different set of place relations (Conradson, 2005). However, this should be acknowledged within the context of an individual's ongoing connections with people and events in other places and times. This approach to research on therapeutic landscapes therefore requires the researcher to observe the broader set of place relations within which an individual is imbricated and to look at longer segments of people's lives than is usual in the field. 


\subsection{Introducing care farms as a therapeutic landscape}

Care farming is defined as the use of commercial farms or agricultural landscapes to provide health (both physical and mental), social or educational benefits through farming (Hine, Peacock and Pretty, 2008). People attending a care farming intervention generally follow a facilitated or structured programme on a regular basis, where the service is usually commissioned by health or social care, or through the use of personal budgets and direct payments. All care farms therefore seek to offer a balance of 'farming' and 'care', where the latter is typically delivered through therapeutic contact with farm livestock, food growing and/or horticultural activities (Hine, Peacock and Pretty, 2008). Care farming is therefore situated within a broader 'green care' movement, a collective term for activities that utilise plants, animals and landscapes to create interventions to improve health and wellbeing (Bragg et al., 2016). To this end, care farming incorporates a number of elements designed for therapeutic benefit. Most notable is contact with nature (and associated therapeutic horticultural and/or food growing activities) and contact with animals.

As with other green care initiatives, such as Social and Therapeutic Horticulture (STH) or eco-therapy, care farming is characterised by the belief that contact with nature is inherently good for you. This is supported by a growing body of evidence which suggests that care farming can confer numerous benefits to individuals, including improved physical health and self-esteem in people suffering from drug of alcohol addiction (Ellings, 2011); reduced signs of anti-social behaviour in young people with behavioural problems (Hassink, Grin and Hulsink, 2013) and overall reductions in anxiety and depression in those suffering from psychological ill- health (Hassink et al., 2010; Pedersen et al., 2011). 
However, there little research to date, which has offered an in-depth exploration of the health and wellbeing effects of care farming for people with intellectual disabilities. This poses a very specific problem. Indeed, care farming is increasingly being advocated as a viable alternative to more traditional forms of health and social care, and over $90 \%$ of care farms in the UK are currently providing services for people with intellectual disabilities (Care Farming UK, 2016). Yet the views and experiences of people with intellectual disabilities (the UK care farm industry's main service user) have rarely been sought (see Rotheram, McGarrol and Watkins, 2017 for recent and notable exception).

Given the current lack of evidence, this visual ethnographic study aims to fill this gap through an in-depth exploration of the therapeutic landscape experiences of people with intellectual disabilities engaged in 'care farming' interventions for health and wellbeing. Careful consideration is also given to the wider impact that engaging in these sorts of activities had on the everyday lives of the participants in this study, over a sustained period of time.

\section{Study design}

\section{The Care Farms}

For this study, three care farm organisations delivering green care services to people with intellectual disabilities were recruited to participate in the research. These settings were selected to reflect the different types of care farms currently in operation in the UK, from commercially orientated or 'real' farms (where care farming constitutes an additional source of funding alongside food production) to farms that offer care services as their main, or sole activity, delivered though charitable organisations or social enterprises. 


\section{Participants}

The study adopted an in-depth and intensive 'case study' approach where individuals were viewed as the 'case studies'. This particular approach was chosen as it allowed the researcher to explore the experiences of people with intellectual disabilities engaged in care farming activities in extensive detail, using a variety of qualitative data sources. Case study participants were selected on the basis that they had recently been enrolled on a care farming programme and were identified as having an intellectual disability. Seven case study participants were recruited in total (see Table 1) each of whom attended a care farm between 1 and 4 days per week. The study also recruited additional individuals that made up case study participants' wider networks of professional and personal relationships. This included staff based at the care farms that participants attended as well as family members and/or paid carers with primary responsibility for supporting case study participants (usually three additional participants were recruited per case study, 13 additional participants in total, see Table 1). 
Table 1. Study participants

\begin{tabular}{|l|l|l|l|}
\hline Name & Age & Gender & Participant Type \\
\hline Jack & 37 & Male & Care farm user \\
\hline Simon & 23 & Male & Care farm user \\
\hline James & 23 & Male & Care farm user \\
\hline Neil & 23 & Male & Care farm user \\
\hline Robert & 46 & Male & Care farm user \\
\hline Eliot & 21 & Male & Care farm user \\
\hline Jed & 21 & Male & Care farm user \\
\hline Lisa & 45 & Female & Care farm staff \\
\hline Liam & 54 & Male & Care farm staff \\
\hline Linda & 54 & Female & Care farm staff \\
\hline Sarah & 60 & Female & Care farm staff \\
\hline Siân & 38 & Female & Care farm staff \\
\hline Sandra & 50 & Female & Care farm staff \\
\hline Wendy & 59 & Female & Parent \\
\hline Cassandra & 63 & Female & Parent \\
\hline Tilly & 58 & Female & Parent \\
\hline Janice & 57 & Female & Parent \\
\hline Matthew & 55 & Male & Carer \\
\hline Saily & 56 & Female & Parent \\
\hline Carol & 53 & Female & Parent \\
\hline
\end{tabular}

Permission to contact potential case study participants was sought through the care farm settings included in this study, after which initial meetings were set up with prospective participants (accompanied by a family member/carer where requested) either at the care farm setting which they attended or at another location of their choosing. When an individual did decide to take part in the research they were then asked to sign a written consent form, produced in an accessible format where necessary. Upon gaining informed written consent from case study participants, the researcher then sought to obtain consent from additional participants associated with 
each case study individual (i.e. parents/carers and care farm staff) following a similar procedure.

The study was reviewed by the [Faculty] research ethics committee and approved by the University Research Ethics committee at [Institution]. Permission to collate visual data, and use participants' identifiable visual images was sought prior to their usage in publications. For this study, pseudonyms are used in place of participants' names in order to ensure participant anonymity.

\section{Data collection}

Data was collated longitudinally over a period of 10 months to ascertain the impacts of care farming on the lives of people with intellectual disabilities over a sustained period of time. The fieldwork phase of this study comprised of two rounds of data collection. The first took place from July 2014 to October 2014, followed by a repeat round approximately six months later, from January to April 2015. This particular research strategy was designed to track participants' progress during their first year on a care farming programme and to gather subjective data on participants' experiences of care farming and any wider impacts of these kinds of activities. To this end, a range of qualitative methods of data collection was used for each case study. These are outlined in more detail below.

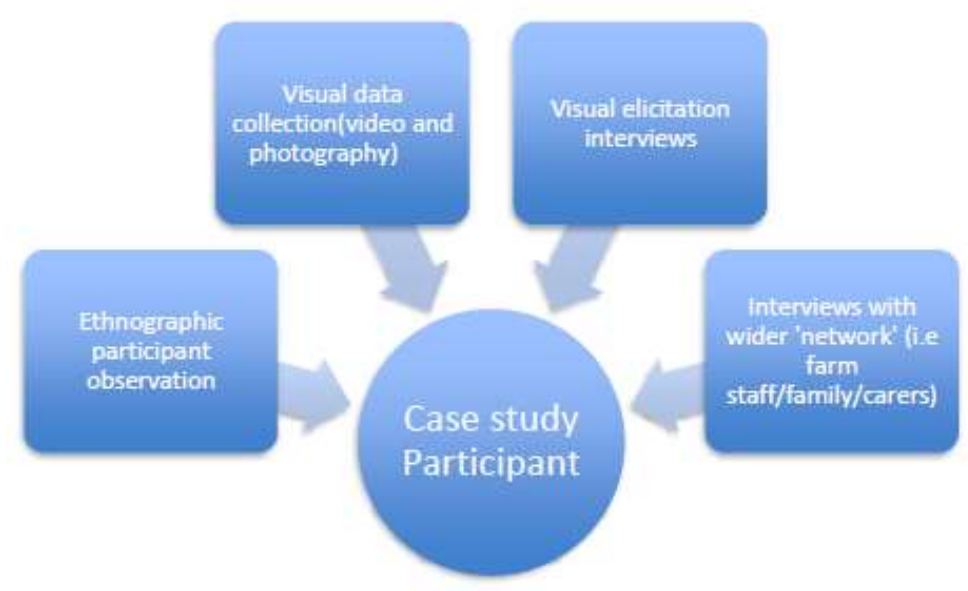


Figure 1 . The case study design

\section{Participant observation}

During fieldwork, a significant period of time was spent at each of the three care farm settings (approximately 30 days, 10 days at each setting). During these visits the researcher collated extensive observational field notes on participants (and the researcher's) behaviour, thoughts, feelings and actions, where these observational field notes primarily performed a supportive and guiding element to the interpretation of interview and visual material and as a resource for researcher reflexivity.

\section{Visual ethnography (film and photography)}

Visual ethnography involves an approach to ethnographic research that engages with audio-visual media and methods throughout the process of fieldwork, analysis and presentation (Pink, 2001). For the study, video data were collated over a period of 10 months, where time was spent with each of the participants at the care farm they attended (approximately eight days per 'case study' participant), video recording them as they went about their normal daily activities. During these sessions, participants were encouraged to 'direct' the content of these videos in ways that reflected their own interests and preferences and were frequently consulted about filming progress, editing options and future activities. The purpose of this part of the research was to capture participants' embodied and multi-sensory place experiences as they engaged with and moved through the care farm environment. To this end, we argue that camera aided participant observation provided a useful means through which to retain some of the material context and detail of the practices under scrutiny. Other studies have also suggested that multi-media methods, like video, are 
potentially more accessible to people with intellectual disabilities, than traditional talk or text-based approaches (Burford and Jahoda, 2012; Cain, Jennings and Poxon, 2013; Sitter, 2015).

In addition to the video data, case study participants were given disposable cameras and asked to take photographs that captured the things that they did and/or places they visited during a 'normal' week. This part of the research was designed to help the researcher access participants' broader set of place experiences, beyond the care farm, in order to ascertain the wider impact that these kinds of encounters had on the everyday lives of participants. It was our intention that this part of the project was to be as user led as possible. Participants were therefore encouraged to take photographs of anything that was of interest to them. Participatory methods such as these have therefore been argued to give people with intellectual disabilities more control over how they represent themselves and how they depict their situation (Booth \& Booth, 2003).

\section{Visual elicitation interviews}

This study also invited case study participants to take part in two qualitative visualelicitation interviews. The first took place soon after participants' enrolment on to the care farm programme, the second approximately six months later. The first stage of the interview involved inviting participants to watch edited versions of their video footage. Selected scenes included those where an individual was perceived by the researcher to be gaining some form of enjoyment or benefit from participation in a particular activity, certain events that may have constituted a negative experience for participants, or scenes that evidenced a change in behaviour or relational capabilities. Immediately following the video element of the interview, participants were then asked to discuss the photographs they had taken with the disposable cameras. The primary purpose of presenting participants with the visual images 
(video and photographs) that they had helped to make, was to provide them with certain visual cues designed to guide the interview process, prompt discussion and provide a basis for reflection. This proved to be an effective method of engaging participants more fully in the interview process, and helped the researcher to elicit a greater depth of response from those participants who may find verbal communication challenging.

\section{Interviews with wider 'network'}

Case study participants' family members and/or carers, as well as care farm staff were asked to participate in two semi-structured qualitative interviews $(n=13,26$ interviews in total) over a 10 month period. These interviews sought to gain the perspectives, views and experiences of case study participants' 'wider network'. Topics discussed included the perceived impact of care farming on case study participants' wider lives, including any perceived changes in mood, behaviour or relational capabilities; social networks (or lack thereof); the impact on relationships with friends or family; participants' emotional wellbeing and any perceived lifestyle changes or improvements to health.

\section{Data analysis}

Both the text based and visual data were analysed using ATLAS ti. Data was analysed using an inductive and interpretive approach which proceeded by carrying out a preliminary reading of the data marking all significant sections of the interviews/video logs, annotating the transcripts and visual material (this included a commentary on non-verbal data i.e. body language and movement, hand gestures and facial expressions). The data was then coded in ATLAS ti using a grounded approach (i.e. allowing codes to emerge from the data, rather than coding a priori) where participants' data was analysed carefully and in substantial detail in order to 
ensure sufficient levels of interpretative engagement with the text. The final set of codes were subsequently analysed and re-grouped into categories based on their common properties. Each case study was analysed separately using this process, in order to ensure that the complexity of individual cases was not lost or subsumed under overarching themes too early. This was followed by a cross case analysis which involved looking for patterns across cases as well as divergences in the data sets. The final set of themes identified was drawn from topics that occurred through the qualitative interviews, ethnographic field notes, video logs/transcripts and theoretical ideas from the literature review.

Strategies for ensuring credibility and trustworthiness in this ethnographic study included processes of triangulation (through using a variety of different data sources and data collection methods); peer debriefing (via project meetings, conferences presentations and research seminars) as well thick descriptions of the phenomena under scrutiny (involving detailed and rich description of individual experiences in order to convey the actual situations that were investigated and the contexts that surrounded them).

\section{Research findings}

\subsection{The care farm as space of security}

A typical day at a care farm is generally structured around a series of set routines and activities. Animals need feeding at the same time every day, and there are various other activities (such as, feed the animals, weeding the plants, cleaning animal pens or collecting eggs) that are regularly performed to ensure the smooth running of a working farm. 

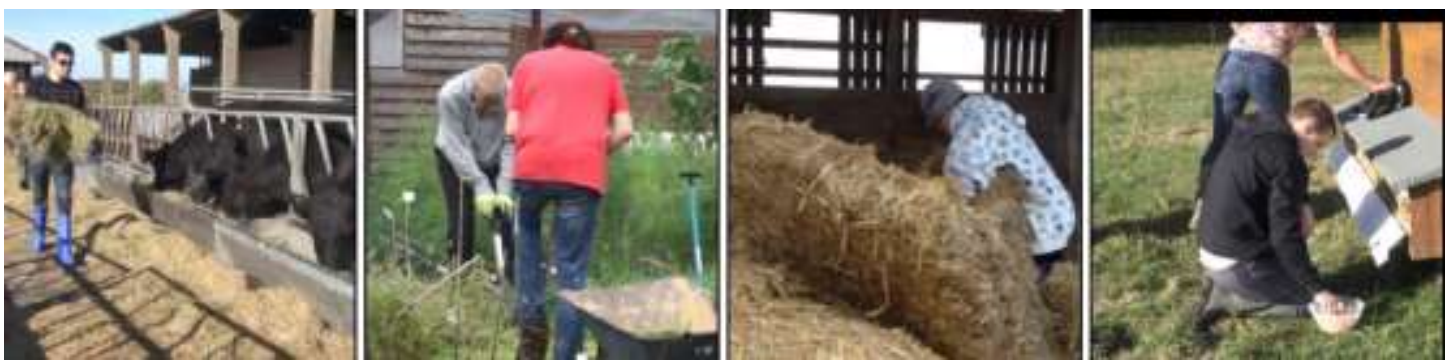

Figure 2. Video frames depicting various care farming activities undertaken by

participants.

Engaging in farm rhythms and routines gave participants the freedom to perform their new identities as farm workers, without fear of discrimination or unwanted surveillance. In this way, participants were able develop their skills and abilities in a safe and secure environment, where they felt accepted and understood.

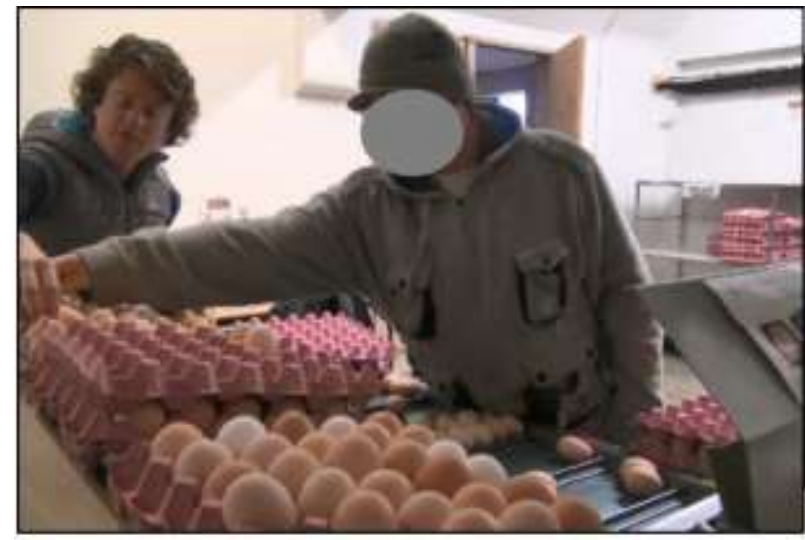

[Talking about collecting and sorting eggs] I think learning all these new skills, it's immensely beneficial for their confidence, because you know it makes them realise wow, OK I am actually good at this (Siân, staff member, interview)

Figure 3. Video frame of Neil sorting eggs ready to be packaged and sold (face obscured at participant's request)

Spending time with farm animals, touching them, feeding them and generally caring

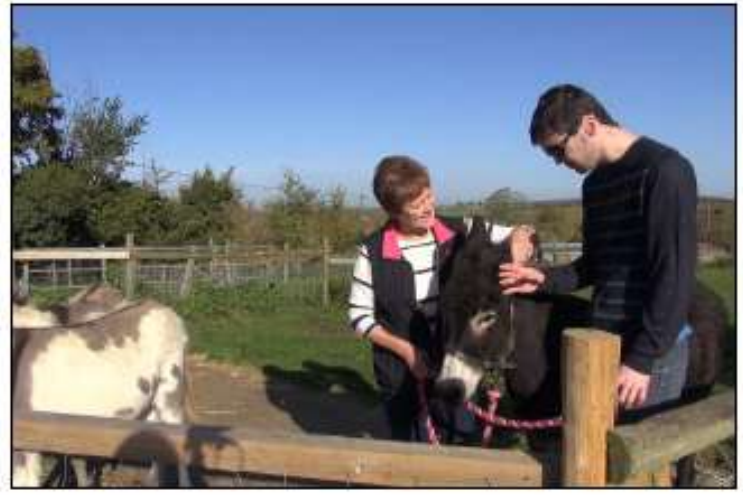

Researcher: So what are you doing in this video? Eliot: Feel happy with the donkeys. Tilly is my favourite. Researcher: And how do you feel, when you are with Tilly? Eliot: I feel calm. (Eliot, participant, visual elicitation interview)

I think if you have animals that are very calm and very passive, which most of our animals are. This has an important impact on our clients. They see the animals being still and calm, just standing there, watching or eating. And it helps them to be more still and calmer, to feel more relaxed (Linda, staff member, interview) 
for them, helped some people to feel calmer or less anxious and provided people with a sense of reassurance, stability and security, through the routines this necessitated. Such explorations therefore draw attention to non-human animals and their role as co-constituents and co-participants of therapeutic spaces (Gorman, 2017).

Figure 4. Spending time with Tilly the donkey

By physically engaging with the land, participants were also able to develop a sense of ownership over these community spaces, a feeling that these spaces were theirs because they had helped to create them.

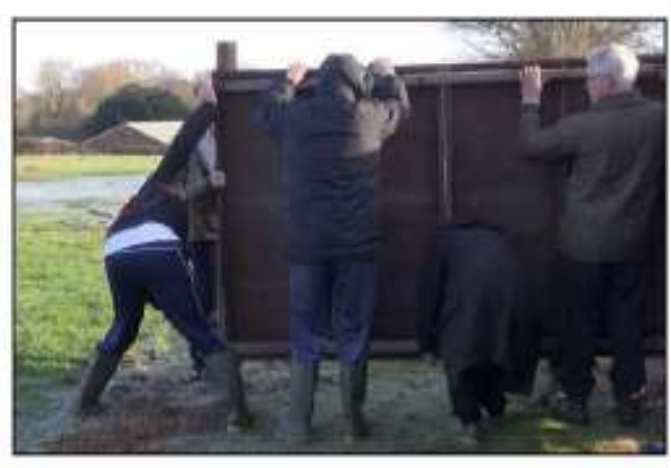

Having been here for quite a while, they actually understand why we're doing a particular activity [...] It's being a part of something, I mean you've got skin in the game if you like and he feels that his skin is in the farm, things that have developed and been moved and built, and they're part of him now, the farm is a part of him and he's got a responsibility for that (Lisa, staff member, interview).

Figure 5. Video frame of care farm users helping to erect a fence for the alpaca enclosure.

Care farming activities therefore have the potential to generate in participants a sense of proximity and immersion though 'direct contact or intimate interactive connection with their environment' (Brown, 2016, p. 6). In this way, participants' landscape experiences served to create a strong or 'authentic' sense of place, a sense that evolved over time as participants continue to engage with features of their environment. 
This sense of place, of feeling 'at home' in comfortable and familiar surroundings, constituted a strong stabilising force for participants and offered them feelings of 'ontological security' (Shaw, 2004; Milligan, Bingley and Gatrell, 2005). This helped some people to feel less anxious and more in control, and participants often described themselves as feeling happier or more able to cope in their everyday lives, as a result of care farming.
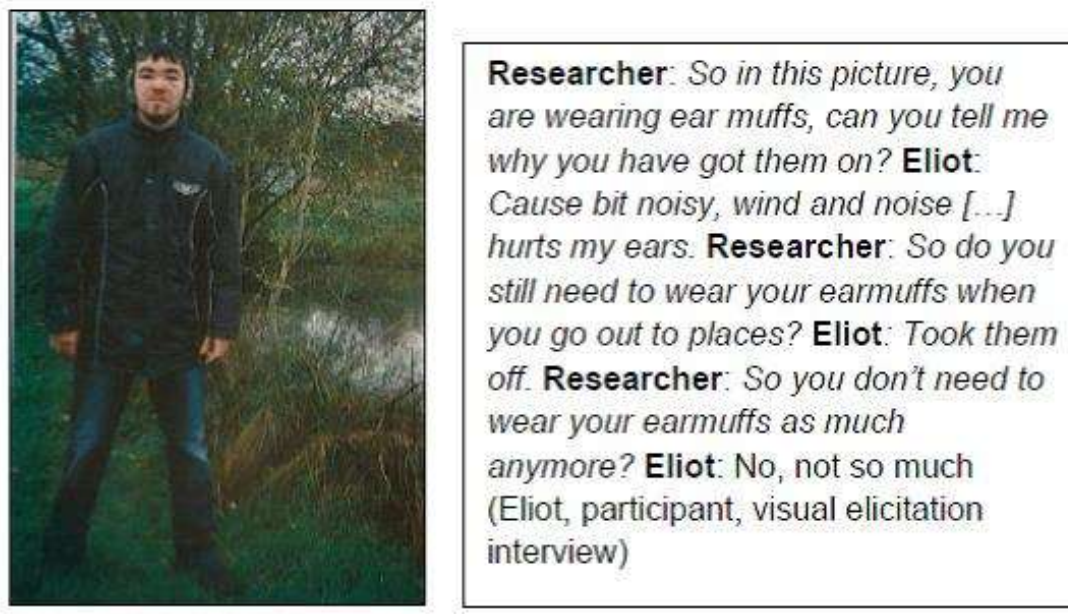

Eliot suffers with the sensory stuff [...] when he first started coming to [care farm B] he found it impossible to be outside without his sunglasses and his ear muffs [..] and this helped him to manage his anxiety. But I think coming to [care farm B] has helped with this [...] being at the farm and spending a lot of time outside around noisy people and noisy farm animals has helped him to build resilience, and because he feels safe here he knows he can cope with all of that and that's helped him to cope better during his non-farm days too [talking about a recent trip on a public bus] the bus was absolutely crowded, he did struggle but he didn't cover his ears [...] you could see he was struggling but he did it (Sarah, staff member, interview)

Figure 6. Photograph of Eliot at his local nature reserve (taken by Eliot's support worker at his request) wearing his earmuffs

However, these experiences did not always transcend beyond the care farm and some of the people who took part in this study did not necessarily feel happier or less anxious when they returned to their ordinary or everyday places.

I know that Neil has difficulties at home. I think he is very close to his mum and relies on her a lot, but they argue a lot which he finds hard and he often 
comes to the farm in an extremely dark mood (Sandra, staff member, interview)

This reflects the fact that many people with intellectual disabilities lead challenging and complicated lives, typified by experiences of isolation and marginalisation, a lack of personal autonomy and inadequate access to appropriate systems of care and support (Power, 2013; Goodley, 2014; Power and Hall, 2017). In this way, the care farm came to represent an important space of refuge for some people; a place where people could go to forget about their fears or anxieties, be supported to engage in activities that they enjoy or to exert more autonomy over their lives.

\subsection{Enhancing social 'relatedness'}

Whilst care farms offered people the opportunity to participate in productive work activities, they also provided a space where people could engage in meaningful social interactions. These kinds of encounters were very important for participants, because they helped them to physically connect with other people and facilitated feelings of belonging and social inclusion. These findings are therefore significant in the context of the wider disability literature, which suggests that people with intellectual disabilities typically experience social, spatial and cultural exclusion in their everyday lives (Hall, 2012; Goodley, 2016; Power and Hall, 2017).

Some of the participants who took part in this study said that care farming had helped them to make friends, and some had even begun to spend time with friends they had made on care farms doing other things, like going to the cinema, going to the pub or attending local football matches. For these individuals, time spent socialising with friends had decreased significantly since leaving school or college leaving them increasingly isolated (one participant had not left the house for seven years prior to attending a care farm). To this end, care farming provided participants 
with new opportunities to form meaningful adult relationships. This was described as having a significant impact on wellbeing, and participants described themselves as feeling happier as a result of having more active social lives.

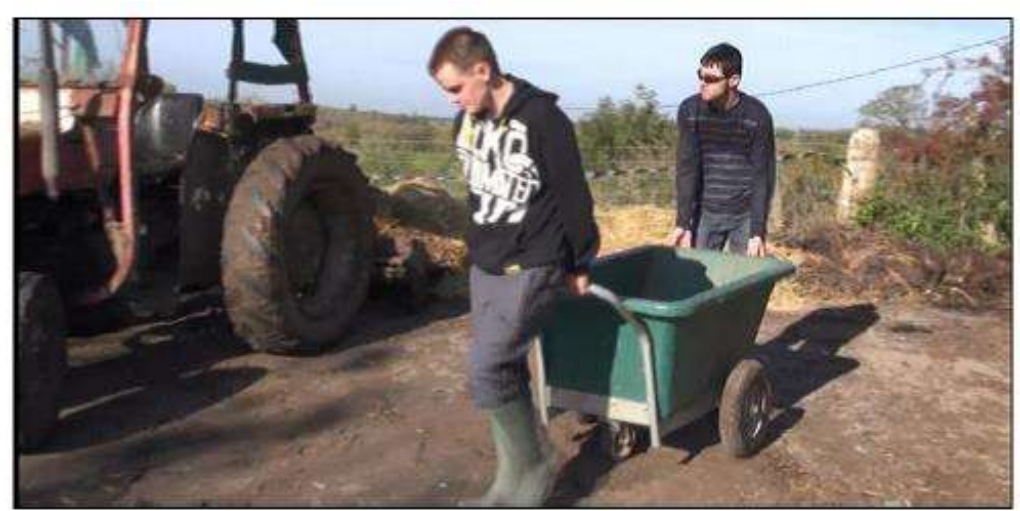

Researcher: And how do you feel when you are asked to help other people? Jed: Um, sociable. Researcher: And why do you feel sociable? Jed: Cause um, l'm doing something in a group. Researcher: So do you feel coming to [care farm B] has helped you to make friends? Jed: Yes. Researcher: And who would you say is a particular good friend here? Jed: Um, Eliot. Researcher: And how do you feel when you spend time with Eliot? Jed: Um, happy. (Jed, participant, visual elicitation interview)

Figure 7. Video frame of Jed helping Eliot to move the wheelbarrow and associated interview extract.

However, not everyone who participated in the study spent time with other users outside of the farm setting. For example, time spent at a care farm was the only time when Neil socialised with anybody his own age. Similarly, whilst Robert said that he got on well with everybody at the farm, he did not appear to have made any particular friends and did not express an inclination to socialise with any of them at other spaces and places. 


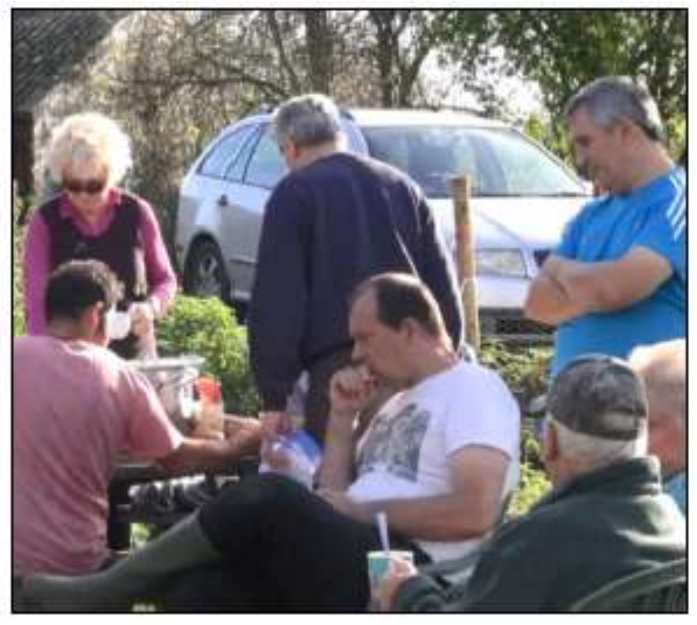

Researcher: [gesturing to video] So have you made any friends since coming here? Robert: Er....(silent pause). Researcher: Is there anyone you get on particularly well with? Robert: No get on with everybody. Researcher: And do you socialise with anyone from the farm, doing other things? Robert: No. I see them here anyway so... (Robert, participant, visual elicitation interview)

Figure 8. Video frame of Robert at a farm social event and associated interview extract

It is also important to note here that people with intellectual disabilities may not always want to spend time with people that do not make up their pre-existing social networks of friends and family, and some participants expressed concerns about speaking to new people because they might not be friendly or nice to them.

Researcher: So how do you feel, when you meet new people? James: Still a bit nervous, sometimes. Researcher: And why is that do you think? James: Cause you gotta be careful [...] don't know if they are nice or gonna stay stuff to you. Researcher: What kind of stuff? James: Dunno, horrible stuff shout out you. Researcher: And how does that make you feel? James: Don't like being out there sometimes. (James, participant, visual elicitation interview)

Forging wider social networks may, therefore, be more difficult to achieve for some people who prefer to utilise the farm space as a space of sanctuary, thereby keeping contact with 'outsiders' or unknown others to a minimum. These findings therefore speak to the therapeutic landscapes literature that identifies a tension between the desire for safe refuge on the one hand, and positive experiences of 'relatedness' or sociality on the other (Brewster, 2014; Butterfield and Martin, 2016; see also Bell et al., 2018). 


\subsection{Enhanced capabilities}

Engaging in care farm activities encouraged participants to move their bodies in new and different ways. Performing rhythmic or repetitive movements, such as digging, weeding or stacking logs, helped participants to embody and retain these skills. Here, the emphasis was on learning through movement rather than verbal instruction. This was perceived to be important for people with intellectual disabilities, who may prefer outdoor-based forms of learning which enable them to retain the knowledge and skills learnt, compared to learning in a traditional classroom environment.

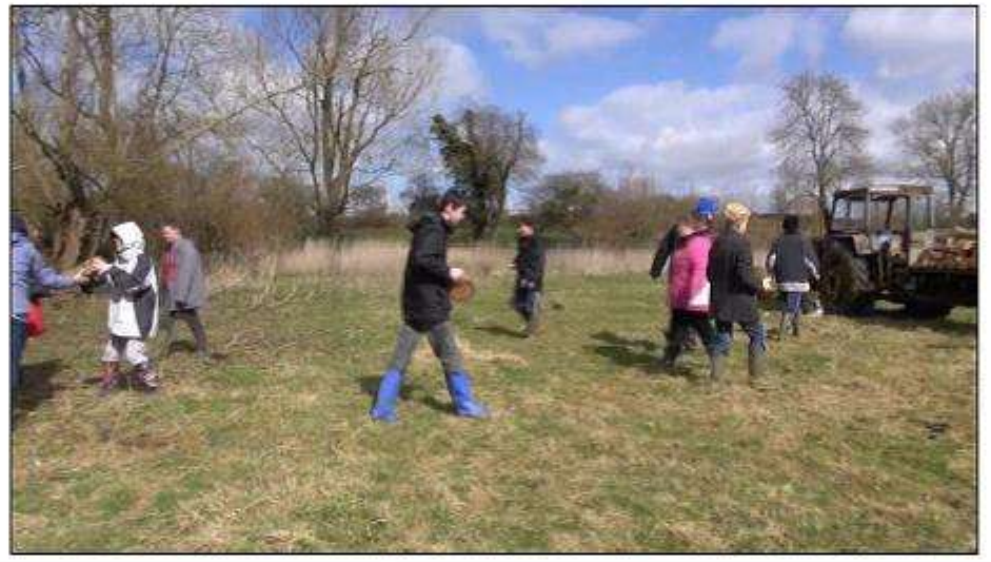

[Talking about the task of stacking logs] when they'd learnt something in September and perhaps not do that job again for six months, it was still there and we found that fascinating as that isn't always usual in a classroom setting. We realised that because we were able to practice plenty, therefore to get those skills under their skin as it were. (Linda, staff member, interview).

Figure 9. Video frame of Eliot and other care farm users helping to stack logs on to the trailer.

As time went on participants began to refine the skills that they had learnt, and embody those activities that they preferred or were particularly good at. In this way, haptic practices of the moving body are seen as a way of coming to 'know thyself' (Husserl, 1989, p. 61) or to feel oneself (Bingley, 2003). Indeed, unlike visual experience, tactile-kinaesthetic experience necessarily entails an interrogation of 
one's own bodily state. This can result in a better understanding of one's own body and its abilities. This in turn, helped participants to feel more confident in themselves and in their ability to do certain things. This included doing things like getting up and getting ready in the morning; making their own lunches; performing household chores, such as cooking or cleaning and helping in the garden.

One thing I have noticed, he will make his own lunches in the morning now and on [care farm A] days, I never have to get him up he gets up and gets ready himself and he's ready to go (Cassandra, parent, interview)

These newfound capabilities encouraged Jack to seek out a new living arrangement, and after three months of attending a care farm he decided to move out of the family home into supported living. This arrangement appears to be working well for Jack. Being away from the 'old man' has helped Jack to feel more like an adult, offering him the space to grow and realise his potential.

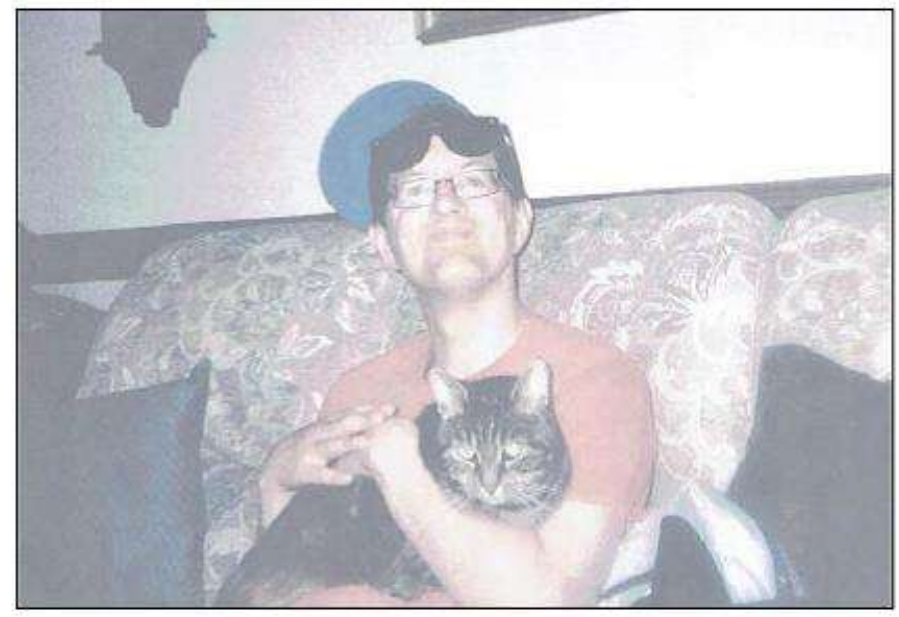

Jack: Its quieter here than it was at home [...] get away from the old man. Researcher: And how does that make you feel, being more independent? Jack: Alright, it's good (Jack, participant, visual elicitation interview)

Figure 10. Photograph of Jack, taken at his new residence, cuddling his landlady's cat.

The rural locations of the care farm settings mean that users are often required to travel some distance to attend and therefore have to plan carefully for how they are 
going to get there each day. For some participants, this motivated them to begin travelling more independently (e.g. by bus or taxi) to care farm settings. This was also shown to encourage people to travel independently when doing other things, like going to the shops or seeing friends and family.

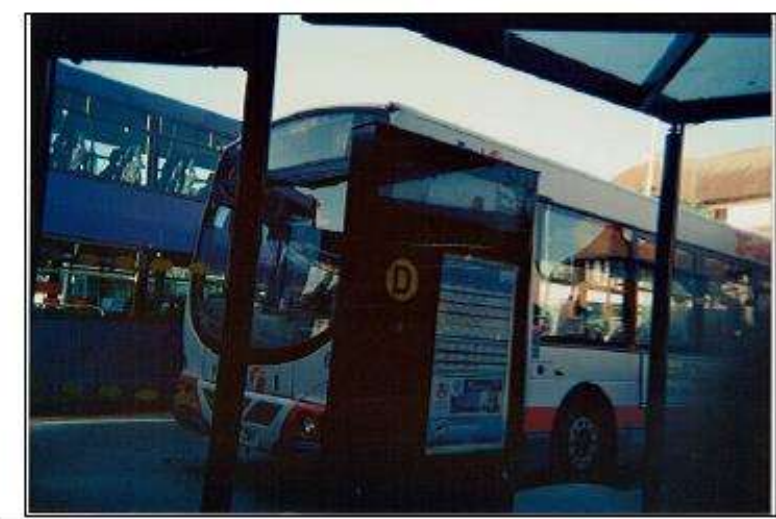

Researcher: So what is going on this picture? James: This is me waiting at the bus stop.

Researcher: And do you get the bus on your own sometimes. James: I didn't before, but I do now [..] go to the shops and that (James, Participant, visual elicitation interview)

And he now gets the bus to [name of place] yeah and I was bit worried [...] but he seems perfectly $O K$ with [...] he goes in to town I think reasonably regularly on his own just to maybe do an errand for his mum, or maybe just to look around the shops (Lisa, staff member, qualitative interview)

Figure 11. Photograph taken by James at the bus stop

As well as providing some people with opportunities to become increasingly independent, spending time with other users at a care farm (and opportunities for socialising that this has afforded) helped some people to feel increasingly confident 'in their bodies. As Jack's journey demonstrates this has had a positive influence on the way in which participants relate to other people in social spaces and situations, beyond the care farm (see figure 12). 


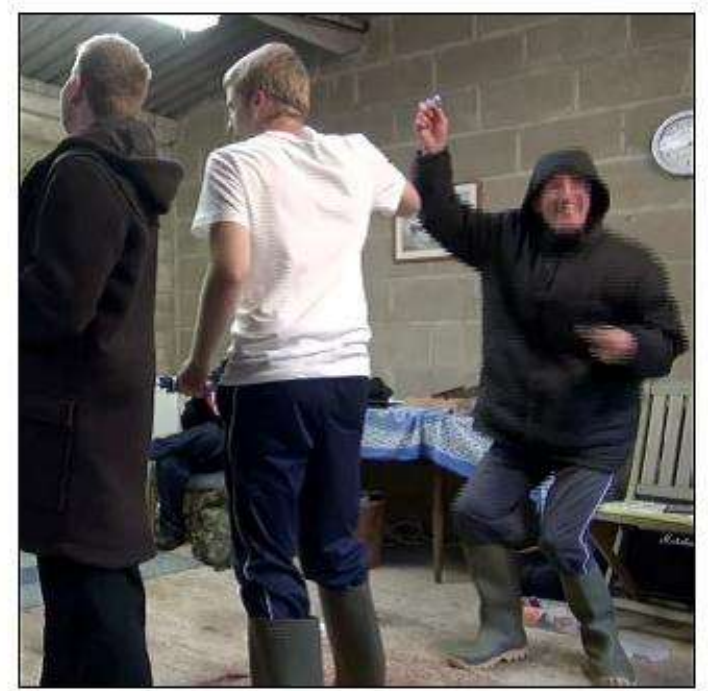

Researcher: So what's going on in this video, what are you doing? Jack: Playing darts. And wiggling. Researcher: Yes and wiggling, or dancing? Jack: Yeah. And smiling Researcher: Yes you are smiling; so did you feel happy during this video? Jack: Yeah [...] never used to dance, [name] is gonna get me to dance at the disco next week. Researcher: And how do you feel about that? Jack: OK, bit nervous [...] might try and dance with this girl. (Jack, participant, visual elicitation Interview)

Figure 12. Video frame of Jack dancing

The idea of being temporarily placed in a new environment characterised by a whole new set of socio-spatial positions and relations therefore demonstrates how persisting relational dependencies that can exist between bodies may be disrupted in ways that 'trip participants out of their performative habitus' (Atkinson and Scott, 2015, p. 79) to open up new and positive possibilities and ways of being.

Whilst some people who took part in this study experienced the care farm as an environment where they could exert more choice and control over their bodies, the experiences that were had in these settings significantly contrasted with the experiences had in other spaces and places (such as the home) characterised by a rather different set of bodily movements, habitual routines and relational dependencies.

For example, Neil has not demonstrated new levels of independence in his everyday life, and still relies on other members of his family to do things like cook his meals, or take him shopping or into town. Similarly, whilst Simon learned to do many different things since attending a care farm and has demonstrated a particular aptitude for woodwork and operating farm machinery, his mother expressed reservations about his ability to be more independent generally, and felt he still needed support to 
perform certain activities around the home. These findings therefore illustrate the challenges of bringing about affective and practical change within people's wider network of social and spatial relationships. Indeed, the ability of care farming to impact on participants' lives outside of the farm is reliant upon active engagement between care farm staff and family members and carers as well as relevant health and social care providers. Developing good working relationships like these is a twoway process that takes time and effort and requires sufficient engagement from all relevant actors in order to achieve real and sustained change.

\subsection{The pursuit of 'healthier' bodies}

As with other outdoor activities, care farming engages users in a range of activities with the potential to improve or enhance physical health and wellbeing. Activities undertaken on care farms, such as feeding and caring for animals, planting and growing food or general maintenance, require more physical effort than activities offered at regular day care centres, and therefore have the potential to stimulate participants to be more active. These findings are significant, given that physical inactivity is one of the key lifestyle factors causing ill health and increased risk of chronic diseases in people with intellectual disabilities (Emerson and Baines, 2010).

Care farming can also encourage some people to be more active generally. Spending prolonged amounts of time outdoors engaging in physically demanding work helped some people who took part in this study to feel fitter and stronger. Jack, for example, is now able to walk for longer distances without getting tired, and he also regularly cycles to places rather than relying on other people to drive him. Similarly, James reported feeling noticeably stronger since taking part in care farming, and has initiated his own exercise regime at home. This demonstrates how care farming activities can confer health benefits beyond the farm setting. 


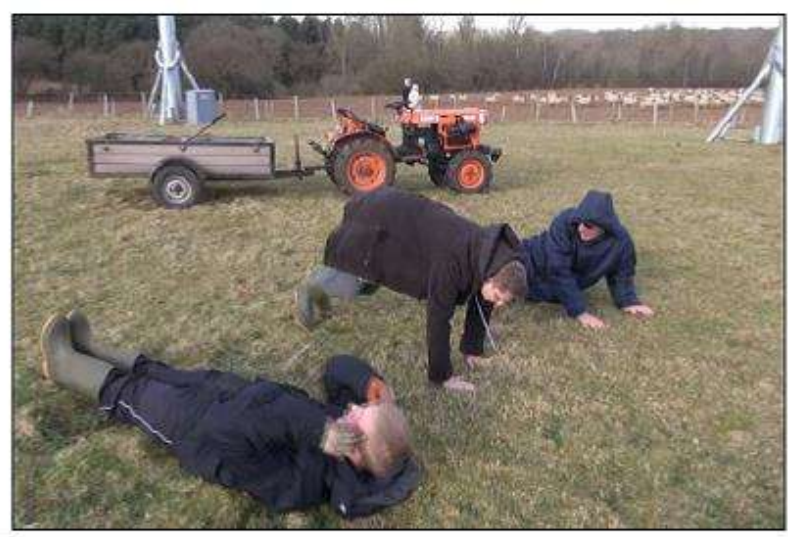

Researcher: So you're about to show them how to do a proper press up? James: Yeah (laughs). Researcher: So we said before how you feel a lot stronger since come to the farm? James: l'm stronger now [...] I lifted a big bag of compost the other day that was heavy. I was digging at 100 miles an hour Monday ... and I'm much broader now [... ] been doing my sit ups and star jumps at home every day (James, participant, visual elicitation Interview)

Figure 13. Video frame of James showing everyone how to do a proper press up

Whilst care farming encouraged some participants to pursue more active lifestyles, other people continued to lead very sedentary lives when not at the farm. For example, whilst Neil demonstrated a willingness and aptitude for physical work, he continues to spend a significant amount of time at home, or in bed. Similarly, Simon, an extremely active and mobile individual on farm days, spends a lot of his spare time 'sitting around the house' watching TV or playing computer games.

Researcher: So what do you do on a normal day at home? Simon: Nothing [...] lay about, play computer games. (Simon, participant, visual elicitation interview)

This reminds us that whilst open outdoor settings can encourage people to move differently (i.e. to be more physically active) these changes do not always transcend to other aspects of participants' lives, especially when they spend a significant amount of time at home (where physical activity is impeded).

Working on a care farm provided participants with opportunities to grow their own food, as well as cooking and eating together. This exposed participants to many 
different tastes, flavours and textures and introduced them to healthier and more varied diets. Introducing participants to new and healthier food options (in particular vegetables and fruit) also had the potential to improve people's general eating habits. Since attending the care farm some participants had begun to eat a healthy and varied diet and had even begun to make suggestions for new recipes to try at home.

Because you know, he loves to cook and try new recipes and he's really creative in that way, he's made us all sorts of things at home (Sally, parent, interview)

However, being exposed to new foods did not always constitute a positive experience for participants, and some people became uncomfortable when offered new foods (even if they ate it at the time it was offered). For these individuals, there is no evidence to suggest that their eating habits have changed significantly since attending a care farm. For example, Neil continued to live on a diet of burgers, spaghetti hoops and crisps when at home, whilst James still preferred to eat white bread (as opposed to whole meal) and declined to eat most things offered to him at the farm.

For some participants then, whilst time spent on a care farm encouraged them to be more active and exposed them to healthier food options during time spent at these settings, these changes did not appear to filter through to other aspects of their lives, thus making the wider health benefits of care farming less clear for these individuals. These findings therefore demonstrate a contrast between the experiences had on the farm (characterised by their own distinct tastes, smells and movements) and other spaces, such as the home environment, characterised by a different set of experiences that may be considered 'health-taking'. 


\section{Discussion: theorising therapeutic journeys}

Within the therapeutic landscapes literature, most studies in this field have tended to focus almost exclusively on the wellbeing benefits of specific 'health giving' sites with very little attention being paid to what happens once participants return to their 'ordinary' or everyday places. As Willis (2009) highlights, this makes it very difficult to ascertain the longer term benefits of these kinds of interventions and calls into question the extent to which so-called therapeutic landscapes are truly transformative, thereby inferring a longer-term impact on health and wellbeing; or merely palliative, implying an immediate but only temporary effect. Whilst Willis (2009) couches this debate in terms of therapy versus palliation, the latter term is generally used in end of life research to refer to specialised medical care for people with serious illness. As such, we argue that the term palliation is not particularly useful when trying to understand the wider impacts of therapeutic interventions (like care farming) on the everyday lives of people with intellectual disabilities (given that the label 'disability' is not tantamount to serious illness). Rather, it is more useful to think of the therapeutic potential of these kinds of interventions in terms of their transformative power and the extent to which they may be considered therapeutic, (implying wider or longer term benefits) or ameliorating (thus making a difficult or challenging situation temporarily better).

As Atkinson and Robson (2012) observed, the transformative potential of therapeutic interventions is generally structured by emplacement and movement such that, 'If one attends to the boundary itself, the emphasis becomes spatial but if one attends to the person making the crossing, the emphasis becomes temporal and processual' (Grimes, 2006). These observations necessitate attention being given to participants' wider networks of material and social relations, which invariably extend beyond the boundaries of the therapeutic settings that are the focus for investigation. 
As illustrated in the previous section, our analysis of the visual data and interview material generated in this ethnographic study presents a rather complicated picture. Indeed, whilst numerous benefits of care farming were identified, the wider impact of care farming on the everyday lives of people with intellectual disabilities was nuanced and varied. By way of organising our ideas about the therapeutic potential of care farms, and the complexities found therein, we therefore suggest that this study has identified two types of therapeutic journal that broadly fit the experiences of study participants. The word 'journey' is used here to communicate the importance of movement between places and to capture the transfer of affectual energies that may play a part in jolting individuals to think and feel differently.

For the first type of journey, the therapeutic landscape experience resides in the ability of activities conducted on the farm to influence other aspects of participants' lives (and vice versa). In this way, we argue that engaging in care farming activities can constitute experiences that are transformative. Such experiences enable 'flow' (Kilroy et al., 2007) between the boundaries of the farm landscape and other spaces, thereby disrupting and destabilising participants' habituated practices. Here the care farm as a therapeutic space can act as a catalyst for change and enable people to become open to new ways of doing and being (Kilroy et al., 2007; Atkinson and Scott, 2015). In such instances, the boundaries between the care farm landscape and other places that people spend their time are fluid and mobile, enabling 'entry into an alternative social encounter in which different rules, different values and different relations apply' (Atkinson and Robson, 2012, p. 1350). Such encounters facilitate the dissolution of existing structures of thought and action such that participants are able to inhabit new identities and new possibilities for being, both at the farm setting and in other places that they inhabit. Being outdoors in all weathers, moving bodies, making friends and sharing new experiences helped some people to feel happier and healthier, enhanced their social networks and introduced new levels 
of independence and personal autonomy to their everyday lives. All these examples therefore demonstrate how the care farm can be a relational and transitional space within which openness is enabled, spaces in which new resources can be built and mobilised for personal wellbeing (Fleuret and Atkinson, 2007).

By contrast there is another type of journey where the therapeutic experience resides in the 'otherness' of the farm landscape. For this type of journey, participants' enjoyment of the various sense experiences described on care farms exposed a contrast between the sensed quality of this place with other spaces and places that participants spend their time, accompanied by their own distinct sights, sounds, tastes and rhythms. Here, the care farm is perceived as a space of sanctuary where participants can feel safe and accepted, thereby providing a much-needed source of respite from other 'health taking' environments that participants inhabit during their everyday lives.

As with the first type of journey, emplacement and movement structure the therapeutic potential of these kinds of experiences. Here however, notions of retreat or withdrawal are key to understanding the perceived benefits of care farming. Indeed, for some people who took part in this study the care farm came to symbolise a place of escape, somewhere to go to in order to feel happier or more relaxed, spend time with other people or be more physically active. This supports other research on therapeutic landscapes that utilises the concept of retreat to explain the therapeutic power of settings such as the holy well (Foley, 2011) and other pilgrimage sites (Gesler, 1992; 1996; 2005) as well as places with a reputation for healing (Gesler, 1992; 2003), yoga centres and other spaces of retreat (Lea, 2008; Conradson, 2011).

This demonstrates the importance of being able to remove oneself from situations that are considered stressful or harmful, and immerse oneself in an entirely new and 
different set of experiences. This may be especially important for people with intellectual disabilities who typically experience marginalisation in so-called 'everyday' spaces and who might, therefore, seek safe spaces of acceptance where they are able to perform habituated routines and identities without fear of unwanted surveillance or discrimination. Whilst providing people with opportunities to remove themselves from places that are perceived to be detrimental to health can have certain therapeutic benefits, the wider impact of care farming on the lives of these participants is, however, less clear. Indeed, whilst these participants typically found care farming to be beneficial in numerous ways, the boundaries between the farm and other places remained relatively fixed thus enabling less 'flow' or movement of affectual energies. This made it more difficult for these individuals to mobilise wider networks and resources in the same way that others had done, and inhibited the transformative potential of these kinds of encounters. Whilst care farming provided these participants with opportunities to engage in a set of enjoyable experiences that helped them to feel happier; assuage feelings of anxiety or distress or to feel more confident in their abilities, when they returned to their ordinary places, there was little evidence to suggest that their lives had changed in any significant way. For some people then, the therapeutic power of the care farm resides in its ability to ameliorate challenging or harmful life situations, thus offering people a temporary site of respite or refuge.

\section{Conclusion}

In the therapeutic landscapes literature, the assumption that certain landscapes are intrinsically therapeutic has received closer scrutiny in recent years (Bell et al., 2018). This has led some key thinkers in the field to argue for a relational approach to therapeutic landscapes (Conradson, 2005; Foley, 2011; Andrews, Chen and Myers, 2014). As we have sought to demonstrate in this paper, a comprehensive relational 
analysis must take into account, not only the specific forms of engagement that take place within any given 'therapeutic' setting, but also the wider network of socioenvironmental relations within which an individual is embedded (Conradson, 2005). In utilising this theoretical approach, we were able to elicit some of the embodied, emotional and social benefits of care farming activities for people with intellectual disabilities, as well as the wider impact that engaging in these sorts of activities had on the everyday lives of participants. We conclude that this approach to research on therapeutic landscapes encourages those working in the field to critically examine the transformative potential of therapeutic interventions in order to "capture the transfer of affectual energies that may play a part in jolting individuals to see and feel differently' (Patterson, 2005, p. 165). This denotes an important development for this sub-field of health geography, not only because it draws attention to the transformative power of the therapeutic encounter, but also the broader socio-spatial environments in which people live and the ways in which they can limit that power.

\section{References}

Andrews, G. J., Chen, S. and Myers, S. (2014) 'The "taking place" of health and wellbeing: Towards non-representational theory.', Social science \& medicine (1982). Elsevier Ltd, 108, pp. 210-22. doi: 10.1016/j.socscimed.2014.02.037.

Andrews, G. J., Evans, J. and McAlister, S. (2013) "'Creating the right therapy vibe": Relational performances in holistic medicine', Social Science and Medicine. Elsevier Ltd, 83, pp. 99-109. doi: 10.1016/j.socscimed.2013.01.008.

Atkinson, S. and Robson, M. (2012) 'Arts and health as a practice of liminality: managing the spaces of transformation for social and emotional wellbeing with primary school children.', Health \& place. Elsevier, 18(6), pp. 1348-55. doi: 10.1016/j.healthplace.2012.06.017. 
Atkinson, S. and Scott, K. (2015) 'Stable and destabilised states of subjective wellbeing : dance and movement as catalysts of transition', Social \& Cultural Geography. Taylor \& Francis, pp. 75-94. doi: 10.1080/14649365.2014.950689.

Bell, S. L. et al. (2018) 'From therapeutic landscapes to healthy spaces, places and practices: A scoping review', Social Science and Medicine. Elsevier, 196(May 2017), pp. 123-130. doi: 10.1016/j.socscimed.2017.11.035.

Bingley, A. (2003) 'In here and out there: Sensations between Self and landscape Self and landscape', Social \& Cultural Geography, 4(3), pp. 329-345. doi: $10.1080 / 1464936032000108940$.

Bragg, R. et al. (2016) A review of nature-based interventions for mental health care.

Brewster, L. (2014) 'The public library as therapeutic landscape: A qualitative case study', Health \& Place, 26, p. 26: 94-99.

Brown, K. M. (2016) 'The haptic pleasures of ground-feel: The role of textured terrain in motivating regular exercise', Health \& Place. Elsevier. doi: 10.1016/j.healthplace.2016.08.012.

Burford, B. and Jahoda, a (2012) 'Do video reviews of therapy sessions help people with mild intellectual disabilities describe their perceptions of cognitive behaviour therapy?', Journal of intellectual disability research: JIDR, 56(2), pp. 179-90. doi: 10.1111/j.1365-2788.2011.01450.x.

Butterfield, A. and Martin, D. (2016) 'Affective sanctuaries understanding Maggie's as therapeutic landscapes', Landscape Research, 41(6), pp. 695-70.

Cain, R., Jennings, P. and Poxon, J. (2013) 'The development and application of the 
emotional dimensions of a soundscape', Applied Acoustics. Elsevier Ltd, 74(2), pp. 232-239. doi: 10.1016/j.apacoust.2011.11.006.

Care Farming UK (2016) Care Farming in the UK and Ireland: State of Play 2015.

Collins, D. and Kearns, R. (2007) 'Ambiguous landscapes: Sun, risk and recreation on New Zealand beaches', in Williams, A. (ed.) Therapeutic Landscapes. Ashgate Publishing.

Conradson, D. (2005) 'Landscape, care and the relational self: therapeutic encounters in rural England.', Health \& place, 11(4), pp. 337-48. doi: 10.1016/j.healthplace.2005.02.004.

Deluze, G. and Guitarri, F. (1987) A Thousand Plateaus: Capitalism and Schizophrenia. University of Minnesota Press.

DeMiglo, L. and Williams, A. (2008) 'A sense of place, a sense of wellbeing', in Sense of Place, Health and Quality of Life. Hampshire: Ashgate Publishing.

Ellings, M. (2011) Effects of care farms: Scientific research on the benefits of care farms for clients.

Emerson, E. and Baines, S. (2010) Health Inequalities and People with Learning Disabilities in the UK : 2010.

Fleuret, S. and Atkinson, S. (2007) 'Wellbeing, health and geography: A critical review and research agenda', New Zealand Geographer, 63(2), pp. 106-118. doi: 10.1111/j.1745-7939.2007.00093.x.

Foley, R. (2011) 'Performing health in place: the holy well as a therapeutic assemblage.', Health \& place. Elsevier, 17(2), pp. 470-9. doi: 
10.1016/j.healthplace.2010.11.014.

Gesler, W. (1996) 'Lourdes: healing in a place of pilgrimage', Health and Place , 2(2), pp. 95-105.

Gesler, W. M. (1992) 'Therapeutic landscapes: medical issues in light of the new cultural geography.', Social science \& medicine (1982), 34(7), pp. 735-46. Available at: http://www.ncbi.nlm.nih.gov/pubmed/1376497.

Gesler, W. M. (1992) 'Therapeutic Landscapes - Medical Issues in Light of the New Cultural-Geography', Social Science \& Medicine, 34, pp. 735-746. Available at: http://www.sciencedirect.com/science/article/B6VBF-469577T-

3P/2/148259be1d27ffa083cc1f3514128eb9.

Goodley, D. (2016) Disability studies: An interdisciplinary introduction. London: Sage Publications.

Gorman, R. (2017) 'Therapeutic landscapes and non-human animals: the roles and contested positions of animals within care farming assemblages', Social \& Cultural Geography, 18(3), pp. 315-335.

Grimes, L. (2006) Rite Out of Place: Ritual, Media, and the Arts. Oxford University Press.

Hall, E. (2012) 'Spaces of social inclusion and belonging for people with intellectual disability', Journal of Intellectual Disability Research, 1, pp. 48-57.

Hassink, J. et al. (2010) 'Care farms in the Netherlands: attractive empowermentoriented and strengths-based practices in the community.', Health \& place. Elsevier, 16(3), pp. 423-30. doi: 10.1016/j.healthplace.2009.10.016. 
Hassink, J., Grin, J. and Hulsink, W. (2013) 'Multifunctional Agriculture Meets Health

Care: Applying the Multi-Level Transition Sciences Perspective to Care Farming in the Netherlands', Sociologia Ruralis, 53(2), pp. 223-245. doi: 10.1111/j.14679523.2012.00579.x.

Hine, R., Peacock, J. and Pretty, J. (2008) 'Care farming in the UK: Evidence and Opportunities', (January).

Husserl, E. (1989) No Title The crisis of European sciences and transcendental phenomenology: an introduction to phenomenological philosophy. Northwestern University Press.

Jones, K. and Moon, G. (1993) 'Medical geography: taking space seriously', Progress in Human Geography, 17(4), pp. 515-524. doi: 10.1177/030913259301700405.

Kearns, R. (1993) 'Place and Health: Towards a Reformed Medical Geography', The Professional Geographer, 45(2), pp. 139-147.

Kearns, R. and Gesler, W. (1998) Putting Health into Place: Landscape, Identity and Well-being. New York: Syracuse University Press.

Kilroy, A. et al. (2007) Towards transformation: Exploring the impact of culture, creativity and the arts on health and wellbeing.

Laws, J. (2009) 'Reworking therapeutic landscapes: the spatiality of an "alternative" self-help group.', Social science \& medicine (1982). Elsevier Ltd, 69(12), pp. 182733. doi: 10.1016/j.socscimed.2009.09.034.

Milligan, C. and Bingley, A. (2007) 'Restorative places or scary spaces? The impact of woodland on the mental well-being of young adults', Health \& place, 13(4), pp. 34 
Milligan, C., Bingley, A. and Gatrell, A. (2005) 'Digging deep: using diary techniques to explore the place of health and well-being amongst older people.', Social science medicine, $\quad 61, \quad$ pp. 1882-1892. Available at: http://www.ncbi.nlm.nih.gov/pubmed/15913863.

Patterson, M. (2005) 'The Forgetting of Touch: Re-membering Geometry with Eyes and Hands.', Journal of the Theoretical Humanities, 10(3), pp. 115-131.

Pedersen, I. et al. (2011) 'Farm animal-assisted intervention for people with clinical depression: A randomized controlled trial.', Anthrozoos, pp. 149-160.

Pink, S. (2001) Doing Visual Ethnography: Images, Media and Representation in Research. London: Sage Publications.

Power, A. (2013) 'Understanding the complex negotiations in fulfilling the right to independent living for disabled people', Disability \& Society, 28(2), pp. 204-217.

Power, A. and Hall, E. (2017) 'Placing care in times of austerity', Social \& Cultural Geography, pp. 1470-1197.

Rotheram, S., McGarrol, S. and Watkins, F. (2017) 'Care farms as a space of wellbeing for people with a learning disability in the United Kingdom', Health and Place. Elsevier Ltd, 48(October), pp. 123-131. doi: 10.1016/j.healthplace.2017.10.001.

Shaw, M. (2004) 'Housing and Public Health', Annu. Rev. Public Health , 25, pp. 397-418. doi: 10.1146/annurev.publhealth.25.101802.123036.

Sitter, K. C. (2015) 'Participatory video analysis in disability research', Disability \& 
Society, 30(6), pp. 910-923. doi: 10.1080/09687599.2015.1057319.

Willis, A. (2009) 'Restorying the self, restoring place: Healing through grief in everyday places', Emotion Space and Society, 2, pp. 86-91. doi: 10.1016/j.emospa.2009.09.001. 